\title{
The influence of Rice Husk Fiber on The Properties of Epoxidized Natural Rubber/ Rice Husk Compounds
}

\author{
Omar S. Dahham ${ }^{1}$, N.Z. Noriman. ${ }^{1,{ }^{*}}$, S.T. Sam. ${ }^{2}, N$. Marwa. Al-Samarrai ${ }^{1}, Z$. Shayfull ${ }^{3,4}, A$. \\ $M$. Alakrach ${ }^{1}$, and $S$. A. Abduati Elnaid ${ }^{1}$ \\ ${ }^{1}$ Center of Excellence Geopolymer and Green Technology (CEGeoGTech), Faculty of Engineering \\ Technology (FETech), Universiti Malaysia Perlis (UniMAP), Level 1 Block S2, UniCITI Alam \\ Campus, Sungai Chucuh, Padang Besar, 02100, Perlis, Malaysia \\ ${ }^{2}$ School of Bioprocess Engineering, Universiti Malaysia Perlis (UniMAP), Kompleks Pengajian \\ Jejawi 3, 02600 Arau, Perlis, Malaysia \\ ${ }^{3}$ School of Manufacturing Engineering, Universiti Malaysia Perlis (UniMAP), Kampus Pauh, 01000 \\ kangar, Perlis, Malaysia \\ ${ }^{4}$ Green Design and Manufacturing Research Group, Center of Excellence Geopolymer and Green \\ Technology (CEGeo Tech), School of Materials Engineering, Universiti Malaysia Perlis (UniMAP), \\ Perlis, Malaysia
}

\begin{abstract}
In this work, curing characteristics, tensile and physical properties of epoxidized natural rubber/ rice husk (ENR-50/RH) compounds were investigated. Different RH loading (10, 20, 30, 40 and 50 $\mathrm{Phr}$ ) and size (fine size at 100-300 $\mu \mathrm{m}$ and coarse size at 5-10 mm) were prepared and used. Results indicated that the scorch time $\left(\mathrm{t}_{2}\right)$ and cure time $\left(\mathrm{t}_{90}\right)$ became shorter with increasing $\mathrm{RH}$ content. In contrast, minimum torque $\left(\mathrm{M}_{\mathrm{L}}\right)$ and maximum torque $\left(\mathrm{M}_{\mathrm{H}}\right)$ increased with increasing $\mathrm{RH}$ content in the rubber compounds. Hardness and crosslink density showed improvement with increasing RH content. Tensile strength (Ts) and elongation at break $(\mathrm{Eb})$ decreased slightly as $\mathrm{RH}$ content increased. However, the fine size of RH recorded better overall properties compared to the RH coarse size at same loading the rubber compound.
\end{abstract}

\section{Introduction}

Epoxidized natural rubber (ENR) is a modified natural rubber (NR), which is derived from cis-1, 4-isoprene. The monomer isoprene (C) and epoxidized isoprene (E) are randomly distributed along the polymer chain [1]. ENR also be known as good compatibilizer for incompatible rubber blend as well as processing aids. With incorporation of ENR 50, the rubber blends inherent improved process ability, stiffness, resilience and also shown excellent oil resistance, reduced air permeability, good damping and wet grip performance [2]. The using of natural rubber by itself in the production of desired products can affect economical and environmental aspect. To minimize these issues, it will be useful if the

* Corresponding author: niknoriman@unimap.edu.my 
rubber is compound with filler, as it could be improved the properties of rubber compound. The conventional filler, such as carbon black and silica have been used widely with rubber, particularly natural rubber for improving of rubber properties. However, the environmental issues and the relatively high cost of this filler urged the scientists to find alternative material.

Currently, natural fillers, such as natural fiber were used to substitute the conventional filler. Natural fibers are produced from agriculture technology as waste products such as grass, leaves, stems, seeds, wood and other form. Most of these fibers comprise cellulose, waxes, lignin and some water-soluble compounds in their structures [3]. In Malaysia, rice husk (RH) is one of largest waste of natural fiber that produced after rice harvest. RH could be classified as usable material for renewable energy as it can be a road to the creation of a green economy.

However, most of RH been wasted by burning, which caused gases emissions such as carbon monoxide and carbon dioxide and made environmental issues. Recently, RH is attracting much attention and has become a significant part in the industry to over come the environmental pollution problem. One of the first trying that used $\mathrm{RH}$ fiber as a reinforcing filler in different types of polymer was reported by Haxo and Mehta. They found that RH could be effectively used as a partial replacement for finer and more reinforcing blacks [4]. Other researcher, such as Ishak et al. studied the potential of rice husk ash after burning (black and white ash) as fillers in epoxidized natural rubber (ENR). They found that the potential of rice husk ash, particularly the white ash, could be exploited further by controlling particle size and particle size distribution, improving filler dispersion and also its surface functionality [5].

Here in, we report the influence of different loading and size of Rice Husk Fiber on the cure characteristics, tensile and physical Properties of Rice Husk/Epoxidized Natural Rubber Compounds.

\section{Experimental}

\subsection{Materials and Samples Preparation}

Epoxidized natural rubber with 50\% epoxidation (ENR-50) were supplied by Rubber Research Institute of Malaysia (RRIM) as a raw material. Zinc oxide, stearic acid, sulfur and N-cyclohexyl-2-benzothiazole sulfonamide (CBS) were supplied by Anchor Chemical Co. (M) Ltd. Rice husk fibers (RH) were supplied by Bernas Malaysia Sdn. Bhd., Simpang Empat, Perlis. All ingredients that used in this research are listed in Table 1. RH fibers were cut and dried under sun exposure for 3 days before use. Two different sizes of RH (150$300 \mu \mathrm{m}$ and 10-20 mm) were prepared using Crusher model RT34 (Chyun Industrial Co. Ltd.) and lab sieves respectively. Two-roll mill X (S) K - 160 X 320 was utilized to mix rubber with other materials based on ASTM D 3184-89. Rheometer (MDR 2000) was used for cure characteristics according to ASTM D 2240-93. Electrically hot press machine was utilized for rubber compounds compression using cure time at $160{ }^{\circ} \mathrm{C}$ and under 30 tonne pressure.

\subsection{Measurement of Properties}

Dumbbell-shaped mold was utilized to form species for tensile test, which was done according to ASTM D412 using universal testing machine (Instron 5582). Shore-A Durometer (Asker, Kobunshi Keiki Co. Ltd) was utilized according to ASTM D-2240-81 to evaluate the hardness values of species. Toluene solvent was used for swelling test 
according to ASTM D3616 and swelling test data were used to calculate the crosslink density of rubber compounds using Flory-Rehner equations [6].

Table 1. The formulation of ENR-50/RH compounds.

\begin{tabular}{|c|c|c|c|c|c|c|}
\hline \multirow{2}{*}{ Ingredients } & \multicolumn{7}{|c|}{ phr } \\
\cline { 2 - 7 } & R0 & R10 & R20 & R30 & R40 & R50 \\
\hline ENR-50 & 100 & 100 & 100 & 100 & 100 & 100 \\
\hline ZnO & 5 & 5 & 5 & 5 & 5 & 5 \\
\hline Stearic Acid & 2 & 2 & 2 & 2 & 2 & 2 \\
\hline CBS & 1 & 1 & 1 & 1 & 1 & 1 \\
\hline Sulfur & 2 & 2 & 2 & 2 & 2 & 2 \\
\hline RH fs & 0 & 10 & 20 & 30 & 40 & 50 \\
\hline cs & & & & & & \\
\hline
\end{tabular}

\section{Results and Discussions}

\subsection{Cure Characteristics}

The variation in scorch time $\left(t_{2}\right)$, cure time $\left(t_{90}\right)$, minimum torque $\left(\mathrm{M}_{\mathrm{L}}\right)$ and maximum torque $\left(\mathrm{M}_{\mathrm{H}}\right)$ values of ENR-50/RH compounds are shown in Table 2 respectively. It is clearly seen that $t_{2}$ became shorter as RH content increased, which mean that the compound of rubber needed less time to reach to vulcanization onset time. This could be attributed to the mobility restriction of the rubber matrix with the mechanical restrain. Nonetheless, RH (cs) shows longer $t_{2}$ than $\mathrm{RH}$ (fs) at same $\mathrm{RH}$ loading indicating that $\mathrm{RH}$ (cs) tendency needed longer time than RH (fs) to coalesce. $t_{90}$ shows same $t_{2}$ tendency. Thus, the increasing of RH content accelerated the vulcanization process of the rubber compound. However, RH (cs) exhibits longer $t_{90}$ than RH (fs) ar same RH loading. This might due to the poor dispersion of RH (cs) hat caused poor interaction between ENR-50 and RH (cs).

In contrast, the values of $\mathrm{M}_{\mathrm{L}}$ and $\mathrm{M}_{\mathrm{H}}$ increased as $\mathrm{RH}$ increases. This was due to the increasing of viscosity as $\mathrm{RH}$ content increases, which in turn led to decrease the chain mobility inside rubber compounds. Thus the processability of the compounds became more difficult. RH (fs) exhibits lower $\mathrm{M}_{\mathrm{L}}$ and $\mathrm{M}_{\mathrm{H}}$ than $\mathrm{RH}$ (cs) at same $\mathrm{RH}$ loading. This was due to better RH (fs) dispersion, which made better compounding process [7].

Table 2. The cure characteristics of ENR-50/RH compounds.

\begin{tabular}{|c|c|c|c|c|c|}
\hline \multicolumn{2}{|c|}{$\mathbf{R H}$} & $\mathbf{t}_{\mathbf{2}}(\mathbf{m i n})$ & $\mathbf{t}_{\mathbf{9 0}}(\mathbf{m i n})$ & $\mathbf{M}_{\mathbf{L}}(\mathbf{d N m})$ & $\mathbf{M}_{\mathbf{H}}(\mathbf{d N m})$ \\
\hline R0 & Control & 2.0 & 9.5 & 4.2 & 20.5 \\
\hline R10 & fs & 0.80 & 6.25 & 5.56 & 26.0 \\
& cs & 1.10 & 6.75 & 6.0 & 28.1 \\
\hline R20 & fs & 0.65 & 6.10 & 7.99 & 29.2 \\
& cs & 0.82 & 6.35 & 11.29 & 30.7 \\
\hline R30 & fs & 0.37 & 5.24 & 11.04 & 31.2 \\
& cs & 0.50 & 5.79 & 12.41 & 33.4 \\
\hline R40 & fs & 0.27 & 5.15 & 12.82 & 35.1 \\
& cs & 0.34 & 5.65 & 13.5 & 37.2 \\
\hline R50 & fs & 0.20 & 5.06 & 13.44 & 38.8 \\
& cs & 0.27 & 5.45 & 13.99 & 40.8 \\
\hline
\end{tabular}




\subsection{Tensile and Physical Properties}

Table 3 shows the tensile strength (Ts), elongation at break (Eb) and modulus at $100 \%$ elongation (M100) of ENR-50/RH compounds. It was observed that the increasing of RH content in ENR-50/RH compounds led to gradual decreases on Ts. Azmi et al. attributed the decreasing of Ts for natural fiber /rubber compounds to the increasing of the stress transmission difficulty from rubber matrix to the filler [8]. However, RH (fs) was higher Ts than RH (cs) at same RH loading. This was due to better RH (fs) distribution in the rubber compounding compared to RH (cs). The percentages Eb decreased as RH loading increased. This decreasing made the compounds stiffer and harder because the mobility of the chain inside rubber compound became more difficult. However, RH (fs) shows higher $\mathrm{Eb}$ than $\mathrm{RH}$ (cs) due to the good corporation of RH (fs) with ENR-50 which in turn led to increase the viscosity of rubber vulcanized and became harder to be fractured. The M100 values increased continuously as RH content increased in the rubber compounds.

According to Sharifah et al. research, M100 value is directly proportional to the crosslink density [9], which mean M100 increases was due to the crosslinking density improvement as shown in Figure 1. This indicated that the incorporation between RH as filler and ENR-50 as matrix enhanced the stiffness of the compound. Additionally, RH (fs) recorded higher M100 values than RH (cs) at same RH loading due to better RH (fs) distribution that gives larger surface area to contact with ENR-50.

Hardness of ENR-50/RH compounds shows same trend of crosslink density, which increased as RH loading increased (Figure 2). Moreover, RH (fs) was higher hardness than RH (cs) at same RH loading, which indicated that the incorporation of RH (fs) with ENR50 matrix has improved the stiffness and brittleness of the rubber compounds more than RH (cs) $[10]$.

Table 3. The tensile properties of ENR-50/RH compounds.

\begin{tabular}{|c|c|c|c|c|}
\hline \multicolumn{2}{|c|}{} & $\begin{array}{c}\text { Ts } \\
\text { (MPa) }\end{array}$ & $\begin{array}{c}\text { Eb } \\
\text { (\%) }\end{array}$ & $\begin{array}{c}\text { M100 } \\
\text { (MPa) }\end{array}$ \\
\hline R0 & Control & 13.0 & 966 & 0.50 \\
\hline R10 & fs & 12.2 & 960 & 0.85 \\
& cs & 8.9 & 841 & 0.75 \\
\hline R20 & fs & 10.6 & 901 & 1.55 \\
& cs & 7.2 & 802 & 1.45 \\
\hline R30 & fs & 8.3 & 814 & 1.85 \\
& cs & 5.7 & 712 & 1.75 \\
\hline R40 & fs & 5.2 & 715 & 2.50 \\
& cs & 2.6 & 614 & 2.35 \\
\hline R50 & fs & 2.4 & 619 & 2.70 \\
& cs & 1.8 & 511 & 2.60 \\
\hline
\end{tabular}




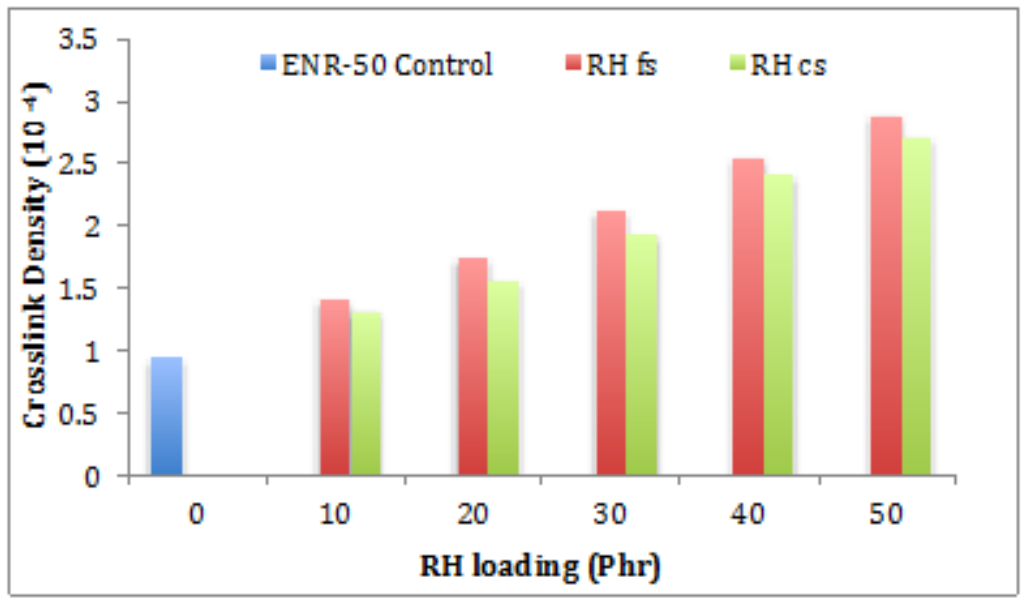

Fig. 1. The Variations of Crosslink density of ENR-50/RS compounds.



Fig. 2. The Variations of Crosslink density of ENR-50/RS compounds.

\section{Conclusion}

Generally, the increasing of RH into ENR-50 gave positive impacts on the cure characteristic, which reduced the scorch and cure time of the ENR-50/RH compounds. Additionally, the maximum torque, modulus and physical properties such as crosslink density and hardness were improved. Tensile strength and elongation at break slightly decreased as RH increased. However, RH (fs) shows better overall properties than RH (cs) at same loading.

The authors would like to acknowledge the Fundamental Research Grant Scheme (FRGS) Phase 1/2015 (9003-00523) under Ministry of Higher Education, Malaysia. 


\section{References}

1. R. Hamzah, M.A. Bakar, M. Khairuddean, I.A. Mohammed, R. Adnan, Molecules, 17, 10974 (2012)

2. N.R. Munirah, N.Z. Noriman, S. T. Sam, C.M. Ruzaidi, M.F. Omar, M.Z. Salihin, Applied Mechanics and Materials, 679, 207 (2014)

3. D.N. Saheb, J.P. Jog, Adv. Polym. Tech., 18, 351 (1999)

4. H.E. Haxo Jr, P.K. Mehta, Rubber Chem. Technol., 48, 271 (1975)

5. Z.M. Ishak, A.A. Bakar, Eur. Polym. J., 31, 259 (1995)

6. P.J. Flory, J. Rehner, Journal Chemistry Physics, 11, 512 (1943)

7. I.L. Hakim, N.Z. Noriman, S.T., Sam, S.A.B. Shahnaz, S. Ragunathan, Advanced Materials Research, 795, 550 (2013)

8. A.A. Azmi, N.N. Zulkepli, M.R. Nordin, M.M.A.B. Abdullah, I. Sandu, M.A.A.M, Salleh, I. Hanafi, Materiale Plastice, 50, 175 (2013)

9. H.A. Sharifah, Composite Science Technology, 65, 525 (2005)

10. O.S. Dahham, N.Z. Noriman, S.T. Sam, M.F. Omar, A. Alakrach, Appl. Mech. Mater., 754, 693 (2015) 